\title{
Radon concentration measurements in sludge of oil fields in North Oil Company (N.O.C.) of Iraq
}

\author{
Shafik S. Shafik, Basim Kh. Rejah, Abdul Hussein Abdul Ameer \\ Department of Physics, College of Science, University of Baghdad, Baghdad, Iraq. \\ E-mail:dr.basim2014@gmail.com
}

\begin{abstract}
In this study the assessment radon concentration in sludge of Oil Fields in North Oil Company (N.O.C.) of Iraq have been studied using CR-39 solid-state nuclear track detector technique. A total of 34 samples selected from 12 oil stations in the company have been placed in the dosimeters. The average radon concentration was found to be $162.29 \mathrm{~Bq} / \mathrm{m}^{3}$ which is fortunately lower than the standard international limit. The potential alpha energy concentration and annual effective dose have been calculated. A proportional relationship between the annual effective dose and radon concentration within the studied region has been certified.
\end{abstract}

Keywords

Radon, CR-39,

Natural Radioactivity, Effective Dose, Sludge.

Article info.

Received: Jan. 2015

Accepted: Jan. 2015

Published: Apr. 2015

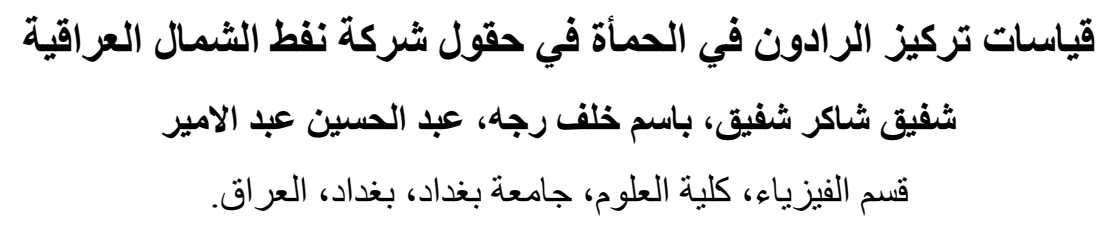

في هذه الدراسة نم تقييم تركيز غاز الرادون في الحمأة المأخوذة من حقول النفط في شركة نفط الثمال (N.O.C)

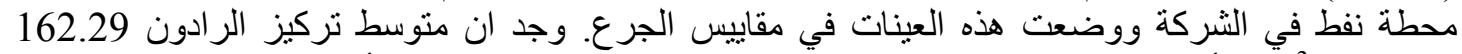

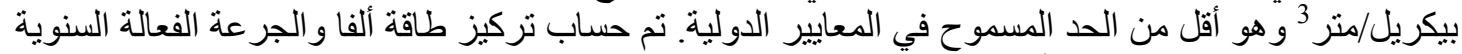

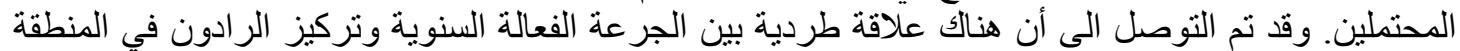
التي شملتها الدر استة.

\section{Introduction}

Radon which is a topic of public health concern has been found to be a ubiquitous indoor air pollutant in homes to which all persons are exposed [1]. Radon has no color, odor or taste and is chemically inert. Its source is from uranium. As the uranium nucleus decays to form stable lead, a process taking many years, it changes from one radioactive element to another in a sequence known as the uranium decay cycle [2]. Radon is the largest and most variable contributor of public exposure to radiation. It is estimated that the annual effective dose by radon and its progeny from the inhalation of air is about $50 \%$ of natural public exposure to high levels of radon can cause lung cancer [3]. Radon can enter buildings through the floor, and in cases where ventilation is poor, the radon concentration can build up to high levels, exposing the occupants via inhalation [4].

Radon is responsible for the majority of the public exposure to naturally occurring radiation. The United Nation Scientific Committee on the Effects of Atomic Radiation (UNSCEAR) reported that radon and its progenies 
cause on average a radiation dose of $1.3 \mathrm{mSv}$ per year and $79 \%$ of the radiation dose is due to the indoor radon inhalation [5]. Therefore, each country makes national surveys of the actual radon concentration and implements radon management measures to protect its citizens [6]. The main source of radon in the air of a dwelling is the ground under buildings, which is responsible for $80 \%$ of the whole radon concentration inside a typical house [7]. Radon concentration in a dwelling mainly depends on the concentration of this gas in ground air, permeability of soil on which the building is erected and tightness of a house construction. Radon concentration in the air of dwellings is subject to seasonal and twenty-four hour variations. Moreover, radon contributes most to the effective annual dose received by people living in the area of normal gamma radiation background [8]. The details of samples for ${ }^{222} \mathrm{Rn}$ measurements, which were collected from each oil field which lies in north region of Iraq, can be illustrated in Table 1.

Table 1: Sludge samples which were collected from each oil field which lies in north region of Iraq.

\begin{tabular}{|c|c|c|c|c|c|c|}
\hline Oil Field & Ajeel & Kotan & Hinjeraa & South of Jumbur & Serbashach & Dawood \\
\hline No. of Samples & $\mathbf{2}$ & $\mathbf{3}$ & $\mathbf{3}$ & $\mathbf{3}$ & $\mathbf{2}$ & $\mathbf{3}$ \\
\hline Oil Field & Baba & $\begin{array}{c}\text { South of } \\
\text { Bi Hassan }\end{array}$ & $\begin{array}{c}\text { North of } \\
\text { Jumbur }\end{array}$ & $\begin{array}{c}\text { North of Bi } \\
\text { Hassan }\end{array}$ & Shoraw & Sarlo \\
\hline No. of Samples & $\mathbf{3}$ & $\mathbf{3}$ & $\mathbf{3}$ & $\mathbf{3}$ & $\mathbf{3}$ & $\mathbf{3}$ \\
\hline
\end{tabular}

\section{Measurement methods}

Can technique with CR-39 type track detectors with $200 \mu \mathrm{m}$ thickness and dimensions of $1 \mathrm{~cm} \times 1 \mathrm{~cm}$ were used in the present study. Dosimeters, was shown in Fig. 1 after an exposure time of 30 days, the dosimeters were collected and chemically etched $(6 \mathrm{~N}$ $\mathrm{NaOH}$ at $70 \mathrm{C}^{\mathrm{o}}$ over 7 hour period) [9]. To account the number of tracks per $\mathrm{cm}^{2}$ occurred in each detector an optical microscope with a magnification of $40 \mathrm{X}$ was used with CCD camera Fig. 2.

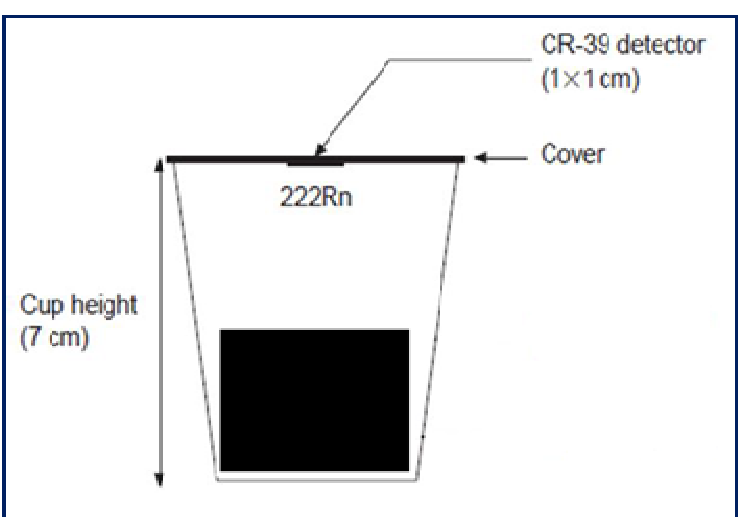

Fig. 1: Schematic diagram showing the geometry of radon dosimeter used in the study.

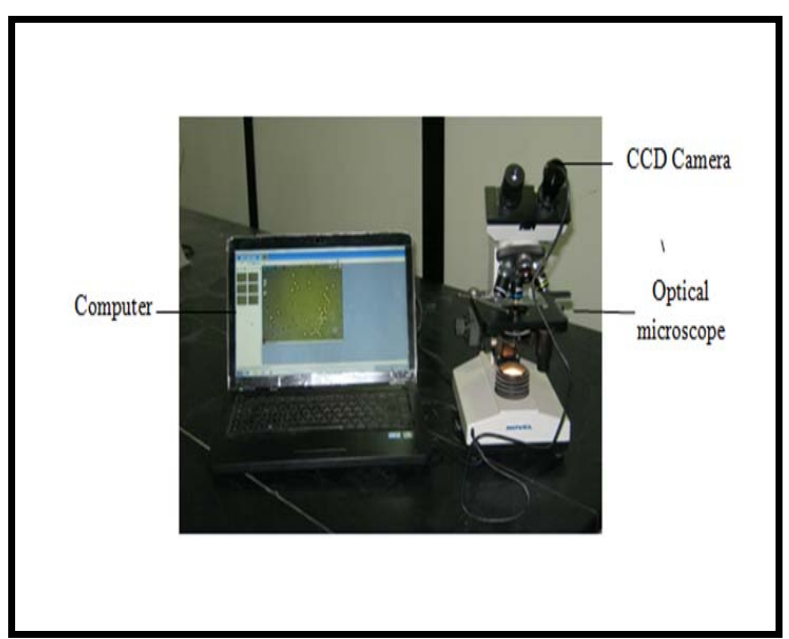

Fig. 2: The track's image in the field view the track counting system. 


\section{Calculations and evaluations}

The CR-39 detectors exposed to the samples will be affected by radon and its daughters in the volume of air around them. In relating the observed track densities to the radon and its daughter activities per unit volume of air, the following equation has been used [10]:

$\rho=x A$

where $\rho$ : is the number of tracks per $\mathrm{cm}^{3}$.

$\mathrm{x}$ : is a constant with dimension of length $(\mathrm{cm})$.

A: is the alpha activity per unit volume (disintegrations per unit time per $\mathrm{cm}^{3}$ ).

The detailed calculation related to the equation has been published earlier [10]. The value of the constant $\mathrm{x}$ is the sum of separate constants calculated for all isotopes $\left({ }^{222} \mathrm{Rn},{ }^{218} \mathrm{Po}\right.$ and ${ }^{214} \mathrm{Po}$ ). In order to estimate the radon concentration, experimental method for radon detection and measurement are based on alpha-counting of radon and its daughters. The track density was calculated in terms of number of tracks per $\mathrm{mm}^{2}$, the average number of tracks was determined by processing an unexposed films CR-39 detector under identical etching condition. The signal measured by etched track detectors is integrated track density, $\rho$ (track. $\mathrm{mm}^{-2}$ ) recorded on the detector, $\mathrm{K}$ the average value of the calibration factor of ${ }^{222} \mathrm{Rn}$ in (Bq. daym ${ }^{-3}$ ) per (tracks. $\mathrm{mm}^{-2}$ ) and $\mathrm{T}$ exposure time (day) has been applied to determine the activity of ${ }^{222} \mathrm{Rn}$ concentration (CRn) in $\mathrm{Bq} / \mathrm{m}^{3}$ using the following Equation [11]:

\section{$\mathrm{CRn}=\rho / \mathrm{T} \mathrm{Ki}$}

where, $\mathrm{Ki}$ is the calibration factor with the dimension of length or equivalent to $\left(\right.$ tracks. $m^{-2} \cdot d^{-1}$ per Bq. $m^{-3}$ ) and $\rho$ is the Track Density.

Almost all measurements of radon levels in the home or outdoors are expressed as the concentration of radon in units of picocuries per liter of air
(pCi/liter), or in SI units as Becquerel per cubic meter $\left(\mathrm{Bq} / \mathrm{m}^{3}\right)$, or radon daughters are expressed in working levels (WL), which is given by [12]:

$C_{P}(W l)=\frac{F C_{R n}}{3700}$

where: $\mathrm{F}$ is the equilibrium factor and recommended as $\mathrm{FC}_{\mathrm{Rn}}=0.4$ [13]. Furthermore Qureshi. [14], proposed a method to calculate the annual effective dose using the Working Level Month (WLM) units, and is given by Eq. (4):

$W L M=\frac{F \times t \times C_{R n}}{170 \times 3700}$

Therefore, the relation between the effective dose and Radon concentration is given by:

$\mathrm{E}_{f f}=\mathrm{G} \mathrm{C}_{\mathrm{Rn}}$

where: $G$ is a constant (conversion factor)

In this study measurement of indoor radon concentration $(\mathrm{CRn})$, potential alpha energy concentration (PAEC) and annual effective dose (HE) have been performed. The potential alpha energy concentration (WL) was calculated using Eq.(3), annual effective dose equivalent (WLM/year) and effective dose also has been calculated using Eqs.(4) and (5), respectively. Exhalation rate was also calculated using the following equation [10]:

$E_{x}=\frac{C_{t} \lambda V}{S\left[t-1 / \lambda\left(1-e^{-\lambda t}\right)\right]}$

where $E x$ is radon exhalation rate $\left(\mathrm{mBq} / \mathrm{m}^{2} . h\right), \quad \mathrm{C}$ is mean radon concentration as measured by CR-39 detector $\left(B q / \mathrm{m}^{3}\right), \mathrm{V}$ is volume of the cane $\left(\mathrm{m}^{3}\right), \mathrm{t}$ is the exposure time, $\lambda$ is the radon decay constant and $\mathrm{S}$ is the surface area from which radon is exhaled into the closed can.

\section{Results}

The overall results for radon concentrations in $\mathrm{Bq} / \mathrm{m}^{3}$, radon exhalation rates in $\mathrm{Bq} / \mathrm{m}^{2} . \mathrm{h}$, the 
equilibrium equivalent ${ }^{222} \mathrm{Rn}$ concentration $\left(\mathrm{C}_{\mathrm{EEC}}\right.$ in $\left.\mathrm{Bq} / \mathrm{m}^{3}\right)$, and the Annual Effective Dose $\mathrm{E}_{f f}$ (in $m S v / y$ ) for thirty four sludge samples from twelve oil stations in the North Oil Company within the governorates of Kirkuk, Salahuddin and Nineveh were given in the Table 2. Radon concentrations were measured by making dosimeter from closed can technique, as shown in Fig. 1, which means that the air at the whole exposure time was confined within the container.

The overall average value of the activity concentrations of ${ }^{222} \mathrm{Rn}$ for sludge samples was $162.29 \mathrm{~Bq} / \mathrm{m}^{3}$. The maximum concentration of ${ }^{222} \mathrm{Rn}$ was $439.68 \mathrm{~Bq} / \mathrm{m}^{3}$ appeared in samples Kotan 3 belonging to Kotan oil station and the minimum concentration was $54.55 \mathrm{~Bq} / \mathrm{m}^{3}$ for the sample Hinjeraa 3 in Hinjeraa oil stations.

The calculated $C_{E E C}$ values showed that the maximum value was 175.87 $\mathrm{Bq} / \mathrm{m}^{3}$ in Kotan 3 sample, which belonging to Kotan oil station, and the minimum value was $21.82 \mathrm{~Bq} / \mathrm{m}^{3}$ in Hinjeraa 3, respectively. The overall average value of $\mathrm{C}_{\mathrm{EEC}}$ for ${ }^{222} \mathrm{Rn}$ was $64.92 \mathrm{~Bq} / \mathrm{m}^{3}$, and this showed that the concentration of radon emitted from the samples does not depend on ${ }^{226} \mathrm{Ra}$ concentration only. The overall average value of the representative (WLM) of ${ }^{222} \mathrm{Rn}$ concentrations for the full sludge sample set were determined to be 0.90 . The highest value was 2.45 in Kotan 3 sample, and the minimum value was 0.3 in Hinjeraa 3 sample. The overall average value of the annual effective dose $\left(\mathrm{E}_{f f}\right)$ obtained for sludge samples set was $4.09 \mathrm{mSv} / \mathrm{y}$, while the maximum value was 11.09 in Kotan 3 sample, and the minimum value was 1.38 in Hinjeraa 3 sample. Fig. 3 showed the relationships between (WLM), Annual Effective Dose $\mathrm{E}_{f f}$ and radon concentration $(\mathrm{Bq} /(\mathrm{kg}))$. From this figure, one can note that the relationships are linear increasing, and useful fitting equations can be deduced;

$\mathrm{E}_{f f}(\mathrm{mSv} / \mathrm{y})=0.0252 \mathrm{C}_{\mathrm{Rn}}\left(\mathrm{Bq} /\left(\mathrm{m}^{3}\right)\right)$

$\mathrm{WLM}=0.0056 \mathrm{C}_{\mathrm{Rn}}\left(\mathrm{Bq} / \mathrm{m}^{3}\right)$

The overall average value of Excess Lung Cancer per Million Persons per Year (ELC) for the full sludge samples set was 2456.7. The highest value was 6655.6 in sample Kotan 3, and the minimum value was 825.7 in sample Hinjeraa 3. Additionally, this disparity in the values is due to differences of the nature of the sludge samples.Fig. 4 shows the relationship between ECL and radon concentration $\left(\mathrm{Bq} / \mathrm{m}^{3}\right)$. From this figure, the fallowing equation is good fitting equation;

$$
\mathrm{ECL}=15.137 \mathrm{C}_{\mathrm{Rn}}\left(\mathrm{Bq} / \mathrm{m}^{3}\right)
$$

\section{Conclusions}

The radon concentration values obtained was varied within the studied zones depending on the height, wide, and ventilation opportunities of Oil Fields in North Oil Company (N.O.C.) of Iraq. The recorded values of radon concentration were lower than the standard limits. A linear relationship has been traced between the annual effective dose and the measured radon concentrations. 
Table 2: The overall results of radon measurements of sludge samples.

\begin{tabular}{|c|c|c|c|c|c|c|c|c|c|}
\hline Sludge & CRn & $\mathbf{F}$ & EEC & PAEC(WL) & EP(WLM/Y) & $E_{\mathrm{ff}}(\mathrm{mSv} / \mathrm{y})$ & ECR & ELC & $\begin{array}{c}\text { Ex } \\
\text { Rate }\end{array}$ \\
\hline Ajeel 1 & 95.04 & 0.4 & 38.02 & 0.010 & 0.42 & 2.40 & 0.0012 & 1150.9 & 0.011 \\
\hline Ajeel 2 & 85.12 & 0.4 & 34.05 & 0.009 & 0.38 & 2.15 & 0.001 & 1030.8 & 0.010 \\
\hline Kotan & $\begin{array}{ll}73.83 \\
\end{array}$ & 0.4 & 29.53 & 0.008 & 0.33 & 1.86 & 0.0009 & 894.1 & 0.008 \\
\hline Hinjeraa 1 & 158.96 & 0.4 & 63.58 & 0.017 & 0.71 & 4.01 & 0.0019 & 1924.9 & 0.018 \\
\hline Hinjeraa 2 & 69.97 & 0.4 & 27.99 & 0.008 & 0.31 & 1.77 & 0.0008 & 847.4 & 0.008 \\
\hline Hinjeraa 3 & 54.55 & 0.4 & 21.82 & 0.006 & 0.24 & 1.38 & 0.0007 & 660.5 & 0.006 \\
\hline South of Jumbur 1 & 380.73 & 0.4 & 152.29 & 0.041 & 1.70 & 9.61 & 0.0046 & 4610.5 & $\overline{0.044}$ \\
\hline South of Jumbur 2 & 224.80 & 0.4 & 89.92 & 0.024 & 1.00 & 5.67 & 0.0027 & 2722.3 & 0.026 \\
\hline South of Jumbur 3 & 171.90 & 0.4 & 68.76 & 0.019 & 0.77 & 4.34 & 0.0021 & 2081.7 & 0.020 \\
\hline Serbashach 1 & 95.04 & 0.4 & 38.02 & 0.010 & 0.42 & 2.40 & 0.0012 & 1150.9 & 0.011 \\
\hline Serbashach 2 & 147.11 & 0.4 & 58.84 & 0.016 & 0.65 & 3.71 & 0.0018 & 1781.5 & 0.017 \\
\hline Dawood 1 & 183.20 & 0.4 & 73.28 & 0.020 & 0.82 & 4.62 & 0.0022 & 2218.5 & 0.021 \\
\hline Dawood 2 & 268.60 & 0.4 & 107.44 & 0.029 & 1.20 & 6.78 & 0.0033 & 3252.7 & $\overline{0.031}$ \\
\hline Dawood 3 & 59.78 & 0.4 & 23.91 & 0.006 & 0.27 & 1.51 & 0.0007 & 723.9 & 0.007 \\
\hline Baba 1 & 150.97 & 0.4 & 60.39 & 0.016 & 0.67 & 3.81 & 0.0018 & 1828.2 & 0.017 \\
\hline Baba 2 & 131.13 & 0.4 & 52.45 & 0.014 & 0.58 & 3.31 & 0.0016 & 1588.0 & 0.015 \\
\hline Baba 3 & 58.95 & 0.4 & 23.58 & 0.006 & 0.26 & 1.49 & 0.0007 & 713.9 & 0.007 \\
\hline South of Bi Hassan 1 & 69.42 & 0.4 & 27.77 & 0.007 & 0.31 & 1.75 & 0.0008 & 840.7 & 0.008 \\
\hline South of Bi Hassan 2 & 294.77 & 0.4 & 117.91 & 0.032 & 1.31 & 7.44 & 0.0036 & 3569.6 & 0.034 \\
\hline South of Bi Hassan 3 & 260.06 & 0.4 & 104.02 & 0.028 & 1.16 & 6.56 & 0.0031 & 3149.3 & $\overline{0.030}$ \\
\hline Kotan 1 & 198.35 & 0.4 & 79.34 & 0.021 & 0.88 & 5.00 & 0.0024 & 2402.0 & 0.023 \\
\hline Kotan 2 & 439.68 & 0.4 & 175.87 & 0.047 & 1.96 & 11.09 & 0.0053 & 5324.5 & 0.051 \\
\hline North of Bi Hassan 1 & 259.79 & 0.4 & 103.91 & 0.028 & 1.16 & 6.55 & 0.0031 & 3146.0 & $\overline{0.030}$ \\
\hline North of Bi Hassan 2 & 208.54 & 0.4 & 83.42 & 0.023 & 0.93 & 5.26 & 0.0025 & 2525.4 & $\overline{0.024}$ \\
\hline North of Bi Hassan 3 & 367.23 & 0.4 & 146.89 & 0.040 & 1.63 & 9.26 & 0.0044 & 4447.0 & 0.042 \\
\hline North of Jumbur 1 & 110.47 & 0.4 & 44.19 & 0.012 & 0.49 & 2.79 & 0.0013 & 1337.8 & 0.013 \\
\hline
\end{tabular}


Table 2: The overall results of radon measurements of sludge samples.

\begin{tabular}{|c|c|c|c|c|c|c|c|c|c|}
\hline Sludge & CRn & F & EEC & PAEC(WL) & EP(WLM/Y) & Eff $_{\text {ff }}(\mathrm{mv} / \mathbf{y})$ & ECR & ELC & $\begin{array}{c}\text { Ex } \\
\text { Rate }\end{array}$ \\
\hline North of Jumbur 2 & 199.73 & 0.4 & 79.89 & 0.022 & 0.89 & 5.04 & 0.0024 & 2418.7 & 0.023 \\
\hline North of Jumbur 3 & 67.49 & 0.4 & 27.00 & 0.007 & 0.30 & 1.70 & 0.0008 & 817.3 & 0.008 \\
\hline Sarlo 1 & 127.00 & 0.4 & 50.80 & 0.014 & 0.57 & 3.20 & 0.0015 & 1537.9 & 0.015 \\
\hline Sarlo 2 & 145.46 & 0.4 & 58.18 & 0.016 & 0.65 & 3.67 & 0.0018 & 1761.5 & 0.017 \\
\hline Sarlo 3 & 174.11 & 0.4 & 69.64 & 0.019 & 0.78 & 4.39 & 0.0021 & 2108.4 & 0.020 \\
\hline Shoraw 1 & 135.82 & 0.4 & 54.33 & 0.015 & 0.60 & 3.43 & 0.0016 & 1644.7 & 0.016 \\
\hline Shoraw 2 & 79.89 & 0.4 & 31.96 & 0.009 & 0.36 & 2.02 & 0.001 & 967.5 & 0.009 \\
\hline Shoraw 3 & 63.64 & 0.4 & 25.45 & 0.007 & 0.28 & 1.61 & 0.0008 & 770.6 & 0.007 \\
\hline
\end{tabular}

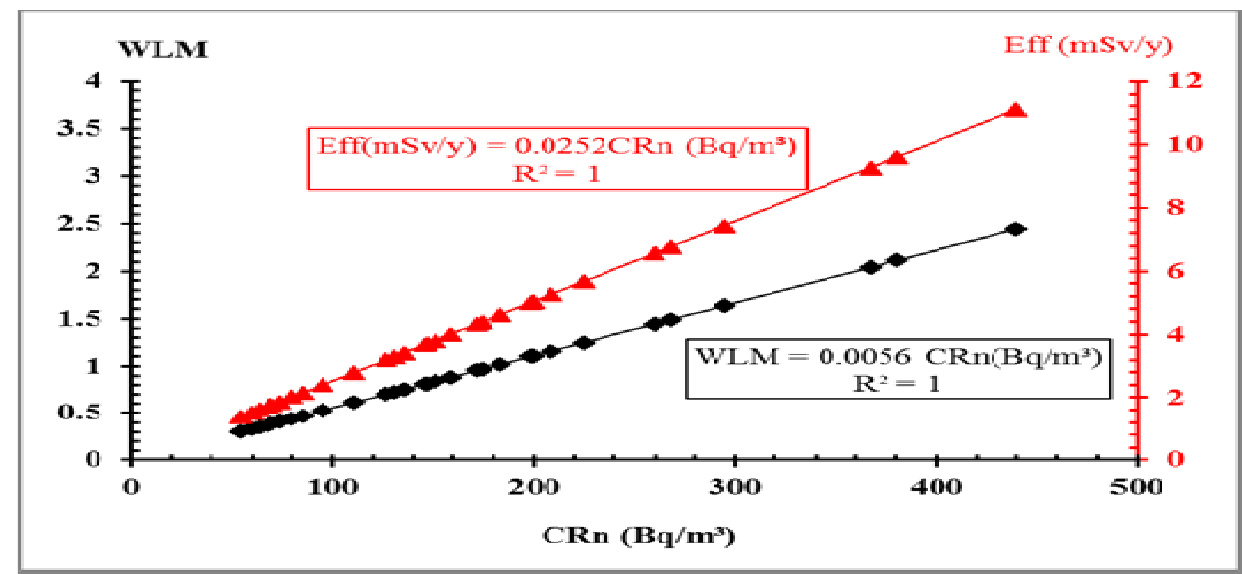

Fig.3: The relationship between working level month (WLM), annual effective dose $E_{f f}$ and radon concentration $(\mathrm{Bq} / \mathrm{kg})$ for sludge samples.

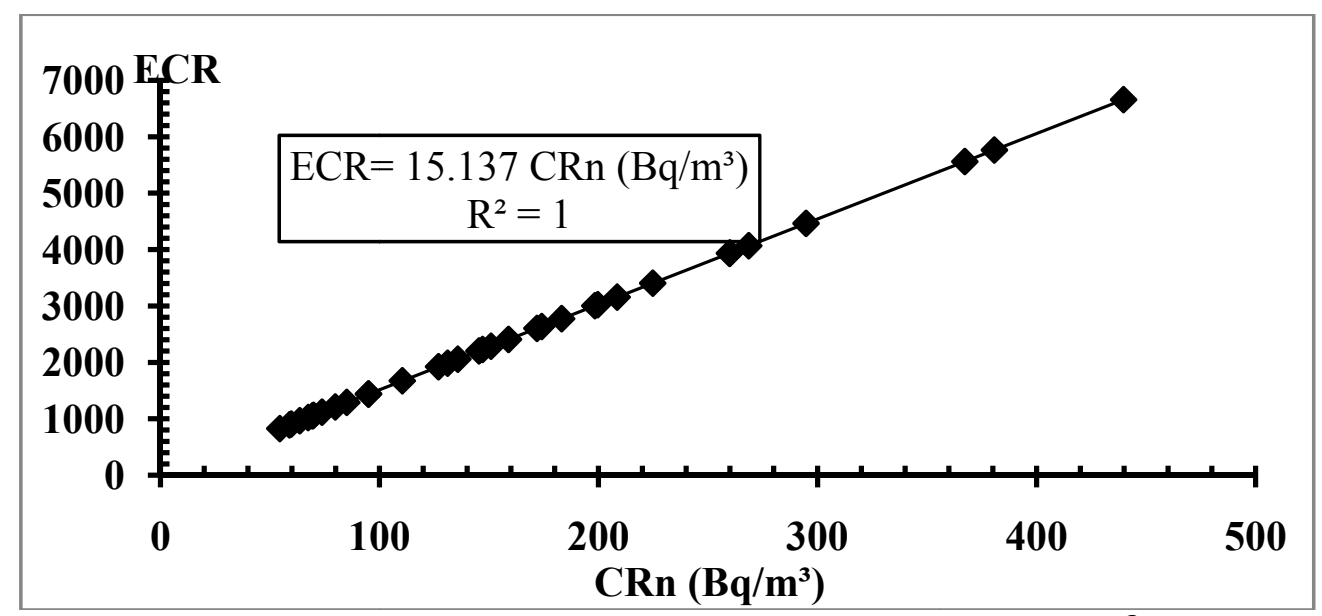

Fig.4: The relationship between $E C L$ and radon concentration $\left(\mathrm{Bq} / \mathrm{m}^{3}\right)$ for sludge samples. 


\section{References}

[1]K. Kant, S.b. Upadhyay, G.S.Sharma and S.K. Chakarvarti. Iran. J. Radiant. Res., 1, 4 (2004) 181186.

[2]H. I. Asaad, M.Sc. Thesis, Univ. of Salahaddin, Iraqi Kurdistan (2004).

[3]A. Gilhoon and J. Al-Kilee, Nuclear Engineering and Technology 37, 4 (2005) 35-46.

[4]A. Birchall, and J.W. Marsh, International Congress Series (2005) 81-84.

[5]J.M.C. Brown, S. Solomon, R.A. Tinker. Journal of Environmental Radioactivity, 102 (2011) 901-905.

[6]Park .C. H.,Cheny W., Guan Z., Zhang Z., Nuclear Technology \& Radiation Protection, 26, 3 (2011) 226232

[7]UNSCEAR."Exposures from Natural Radiation Sources". New Yourk, UN., (2000).

[8]K. Kozak., J. Mazur, B. Kozlowska and M. Karpinska, Applied Radiation and Isotopes, 69 (2011)1459-1465.
[9] M. Younis, Atia, Khetam AbdAlade, B. H. Mahood and A. M. Hssoni, Journal of Basra Searches , 6, 36 (2010).

[10]F. Abu-Jarad, J. h. Fremlin, and R. Bull, Phys. Med. Biol. 25, (1980) 683694.

[11] A.F. Hafez, A.S. Hussein, and N.M. Rasheed, Applied Radiation and Isotopes, 54, (2001) 291-298.

[12]A.J. Khan, A.K. Varhney, R. Prasad, R.K. Tyagi and T.V. Ramachandran, Nucl. Tracks. Radiat. Meas., 17 (1990) 497-502.

[13]UNSCEAR (United National Scientific Committee on the Effects of Atomic Radiation), Report to the General Assembly, United Nations, New York, (2010).

[14]A.A. Qureshi, D.M. Kakar, M. Akram, N.U. Khattak, M. Tufail, and K. Mehmood, Journal of Environmental Radioactivity, 48, 2 (2000) 203-209. 